\title{
I solation and antibiogram of Staphylococcus, Streptococcus and Escherichia coli isolates from clinical and subclinical cases of bovine mastitis
}

\author{
Nihar Nalini Mohanty, Priyaranjan Das, Shaswati Subhadarsini Pany, Laxmi Narayan Sarangi,
} Siddharth Ranabijuli and Hemant Kumar Panda

\begin{abstract}
1. Department of Veterinary Microbiology, College of Veterinary Science and Animal Husbandry, Orissa University of Agriculture and Technology, Bhubaneswar, Odisha, India; 2. Orissa Biologicals Products Institute (SatelliteUnit), Berhampur, Odisha, India; 3. Department of Veterinary Microbiology, Guru Angad Dev Veterinary and Animal Science Univerisity, Ludhiana, Punjab, India; 4. Krishi Vigyan Kendra, Sakhigopal, Odisha, India; 5. Indian Veterinary Research Institute, Izatnagar - 243122, Uttar Pradesh, India; 6. Department of Veterinary Microbiology, College of Veterinary Science and Animal Husbandry, Orissa University of Agriculture and Technology, Bhubaneswar, Odisha, India

Corresponding author: Nihar Nalini Mohanty, email: just nihar@rediffmail.com

Received: 17-05-2013, Revised: 02-07-2013, Accepted: 03-07-2013, Published online: 11-08-2013
\end{abstract}

doi: 10.14202/vetworld.2013.739-743 How to cite this article: Mohanty NN, Das P, Pany SS, Sarangi LN, Ranabijuli S and Panda HK (2013) I solation and antibiogram of Staphylococcus, Streptococcus and E. coli isolates from clinical and subclinical cases of bovine mastitis, Veterinary World 6(10): 739-743.

\begin{abstract}
Aim: The present study was aimed to isolate and evaluate the continuous change in the pattern of drug resistance showed by different mastitogenic organisms, isolated from clinical and subclinical cases of mastitis.

Materials and Methods: The study was carried out using 150 milk samples received from various clinical and subclinical cases, from which the causative organisms were isolated and subjected to in vitro antibiotic sensitivity test.

Results: The bacteriological analysis of the samples indicated the presence of both Gram positive and Gram negative organisms followed by isolation of isolates like Staphylococcus, E. coli, Streptococcus, Bacillus, Corynebacterium, Listeria, Klebsiella. The in vitro sensitivity of Staphylococcus, E. coli and Streptococcus isolates revealed that they were more sensitive towards newer antimicrobials like Levofloxacin and Enrofloxacin.
\end{abstract}

Conclusion: The prevalence of Staphylococcus was found to be maximum followed by Streptococcus and E. coli among the isolated organisms. Levofloxacin and Enrofloxacin were found to be most effective against the targeted isolates.

Key words: antibiotic sensitivity pattern, bovine, mastitis, milk.

\section{I ntroduction}

Mastitis is a multi-etiological complex disease which is characterized by physical, chemical and bacteriological changes in milk and pathological changes in glandular tissue of udder [1]. It is a devastating disease haunting the dairy industry worldwide and is a matter of great concern for leading milk producing country like India because of the losses incurred due to high morbidity, discarded milk, treatment costs and reduced milk production, thus drawing in more attention towards its treatment and control. It has also been found out that mastitis alone contributes to $70 \%$ of the losses during milk production which could have been avoided by means of prompt curative and control measures [2]. Particularly the Indian dairy industry suffers a monetary blow of over Rs. 6000 crores per year [3]. Apart from the economic losses, mastitis can have serious implications on public health. Mastitis which is mostly caused by the interaction of multiple pathogenic agents (primarily bacteria), can expose human beings to various morbific organisms through infected milk, thus serving as a media for transmission of various zoonotic diseases

Copyright: The authors. This article is an open access article licensed under the terms of the Creative Commons Attribution License (http://creativecommons.org/licenses/by/2.0) which permits unrestricted use, distribution and reproduction in any medium, provided the work is properly cited. like T.B, brucellosis, diphtheria, scarlet fever and Q fever [4]. Now there has also been increasing evidence of bidirectional transmission of Methicillin Resistant Staphylococcus aureus (MRSA) in humans and animals. Once exposed to MRSA, animals become reservoir of infection for human beings. So the increased antimicrobial resistance of the organisms in animals treated with antibiotics and their zoonotic transmission continues to be a matter of great concern globally [5]. The success of bovine mastitis therapy basically depends on the understanding of clinical presentation and antimicrobial susceptibility of the etiological agent, among various other factors [6]. One important reason for therapy failure in the management of mastitis could arise from various factors involving pathological changes in the udder, etiology, lower efficacy of antimicrobials, and improper veterinary services [7]. But above all, antimicrobial susceptibility testing, typically using a disk diffusion assay is often performed as part of the routine laboratory evaluation of milk samples with an attempt to provide guidelines for the treatment of mastitis, especially identification of the pathogens causing clinical and subclinical mastitis and thus forming a crucial part in development of mastitis control program. OIE has also recommended monitoring and observation of effectivity of antimicrobials towards pathogenic and commensal bacteria affecting animals [8]. 


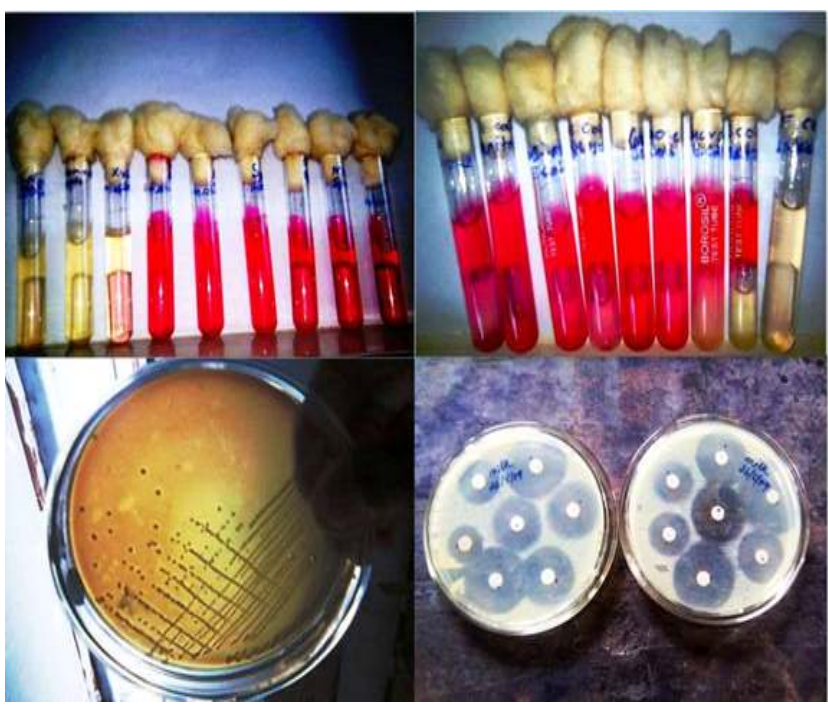

Figure-1. From top left to right: Sugar fermentation test to identify Staphylococcus spp, Sugar fermentation test to identify E.coli, Haemolytic colonies of Streptococci spp on blood agar, Antibiotic sensitivity test of the isolates.

Since the isolation of organism and choice of antimicrobial agent is often considered empirical in the management of mastitis, the present study was conducted to observe the sensitivity and resistance profile of mastitis causing isolates (particularly Staphylococcus, Streptococcus and Escherichia coli) within and around Bhubaneswar, against various commonly used antimicrobials.

\section{Materials and Methods}

Milk samples $(\mathrm{n}=150)$ from clinical and subclinical cases of mastitis were received by Department of Microbiology, College of Veterinary Science and Animal Husbandry, Orissa University of Agriculture and Technology, from various regions of Bhubaneswar and areas around, for isolation, identification and antibiogram of the mastitogenic organisms during the period from 06.01.2009 to 05.08.2011. All the samples were showing positive result for Modified California Mastitis test. Each sample was taken by means of a sterile inoculating loop and introduced into liquid media (BHI broth) and incubated for substantial growth of microorganisms. Following growth in broth a loopful of culture was streaked onto muller hinton agar (MHA), eosin methylene blue (EMB) agar, mannitol salt agar (MSA), and blood agar and incubated for $24-48$ hour at $37^{\circ} \mathrm{C}$. The different colonies were marked and noted basing on their colony characteristics and growth on selective media. The colonies on blood agar were further analyzed basing on the hemolytic pattern. The morphological and staining characteristics of the organisms were determined by microscopic examination of Gram stained smears and a tentative analysis regarding the type of isolates was made. The isolates were identified according to cultural, morphological and biochemical characteristics complying with methods of Cruickshank [9]. The biochemical test and sugar fermentation properties for identification of isolates were conducted as per

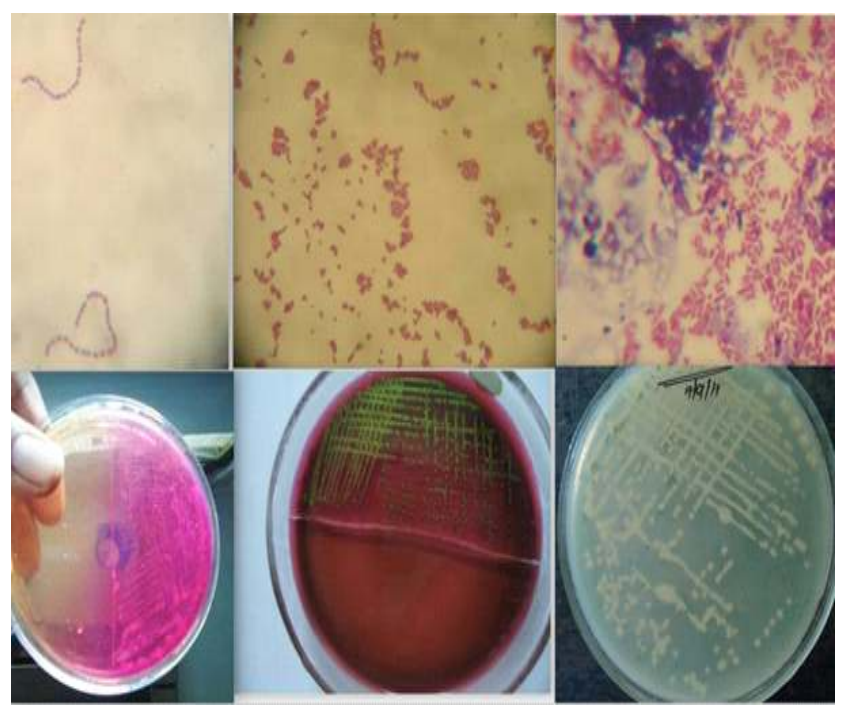

Figure-2. From top left to right: Streptococcus spp, Staphylococcus spp, Gram negative bacilli, colony growth on mannitol salt agar, Metallic sheen on EMB agar by E.coli isolates, colonies on MHA agar.

standard protocol $[10,11]$.

The in vitro antibiotic sensitivity pattern was studied by Kirby-Bauer disc diffusions method using 13 number of antibiotic discs (Himedia) such as Levofloxacin (5 mcg/disc), Enrofloxacin (5 mcg/disc), Penicillin-G (10 units/disc), Streptomycin $(10 \mathrm{mcg} /$ disc), Gentamicin (10 mcg/disc), Oxytetracycline (30 $\mathrm{mcg} / \mathrm{disc})$, Chloramphenicol (30 $\mathrm{mcg} / \mathrm{disc})$, Ceftriaxone tazobactum (30 mcg/disc), Cefixime (30 $\mathrm{mcg} / \mathrm{disc}$ ), Cephalexin (30 mcg/disc), Amoxycillin (10 $\mathrm{mcg} / \mathrm{disc}$ ), Ciprofloxacin (5 mcg/disc), Ofloxacin (5 $\mathrm{mcg} / \mathrm{disc}$ ). The inoculum was prepared by transferring 4-5 colonies from pure culture to BHI broth and incubated at $37^{\circ} \mathrm{C}$ for $6-8$ hours until moderate turbidity developed. Then the inoculums turbidity was matched with standard $0.5 \mathrm{McF}$ arland and diluted with NSS if required. The standardized inoculum was then applied onto the MHA agar plate by soaking with sterile cotton swab and allowed the inoculums to dry. The discs were then placed aseptically equidistant from each other on the surface of the agar plates. The plates were incubated at $37^{\circ} \mathrm{C}$ for $24-48$ hours for development of inhibition zone. The diameters of zone of inhibition were then measured in millimeter and noted down [12]. The interpretation regarding the degree of susceptibility (resistant, moderate and highly sensitive) was made as per Clinical and Laboratory Standards Institute (formerly NCCLS) chart provided by the antibiotic disc manufacturer.

\section{Results and Discussion}

I dentification \& isolation of organisms: Out of the 150 samples processed, 6 are found to be sterile as no growth was observed in liquid and solid media, which may have been due to prior medication before collection of milk from the udder [13]. Bacteriological screening of the samples revealed 17 samples being pure cultures whereas the remaining 127 invariably showed the presence of mixed cultures, which may be 
Table-1. Frequency of isolation of Staphylococcus, Streptococcus and E. coli from clinical samples of mastitis

\begin{tabular}{llll}
\hline Sr. no. & Bacterial species & $\begin{array}{l}\text { No. of isolates } \\
\text { out of 144 non } \\
\text { sterile samples }\end{array}$ & $\begin{array}{l}\text { Approx. } \\
\text { percentage }\end{array}$ \\
\hline 1 & Staphylococcus spp. & 68 & 47 \\
2 & Streptococcus spp. & 46 & 32 \\
3 & E.coli & 30 & 21 \\
& Total & 144 & \\
\hline
\end{tabular}

Table-2. Overall antimicrobial succeptibility profile

\begin{tabular}{lccc}
\hline Antibiotic & $\begin{array}{c}\text { Highly } \\
\text { sensitive (\%) }\end{array}$ & $\begin{array}{c}\text { Moderately } \\
\text { sensitive (\%) }\end{array}$ & Resistant (\%) \\
\hline Chloramphenicol & 77.7 & 11.8 & 10.4 \\
Amoxycillin & 6.94 & 38.19 & 54.86 \\
Enrofloxacillin & 87.5 & 10.4 & 2.08 \\
Streptomycin & 24.30 & 46.52 & 29.16 \\
Levofloxacin & 90.27 & 6.94 & 2.77 \\
Pencillin-G & 0 & 21.52 & 78.47 \\
Gentamicin & 65.97 & 31.94 & 2.08 \\
Ciprofloxacin & 80.55 & 16.66 & 2.77 \\
Ofloxacin & 51.38 & 34.02 & 14.58 \\
Cephalexin & 9.72 & 24.30 & 65.97 \\
Oxytetracycline & 15.97 & 51.38 & 32.63 \\
Cefixime & 4.86 & 29.86 & 65.27 \\
Ceftriaxone+tazobactum & 61.11 & 24.30 & 14.58 \\
\hline
\end{tabular}

Table-4. Antibiogram of Streptococcus isolates

\begin{tabular}{lccc}
\hline Antibiotic & $\begin{array}{c}\text { Highly } \\
\text { sensitive (\%) }\end{array}$ & $\begin{array}{c}\text { Moderately } \\
\text { sensitive (\%) }\end{array}$ & Resistant (\%) \\
\hline Chloramphenicol & 69.56 & 15.21 & 15.21 \\
Amoxycillin & 2.17 & 41.30 & 56.52 \\
Enrofloxacillin & 89.13 & 10.86 & 0 \\
Streptomycin & 26.08 & 32.60 & 45.65 \\
Levofloxacin & 89.13 & 6.52 & 2.17 \\
Pencillin-G & 0 & 39.13 & 60.86 \\
Gentamicin & 65.21 & 34.78 & 0 \\
Ciprofloxacin & 86.95 & 13.04 & 0 \\
Ofloxacin & 43.47 & 32.60 & 34.78 \\
Cephalexin & 13.04 & 21.73 & 56.52 \\
Oxytetracycline & 17.39 & 71.73 & 10.86 \\
Cefixime & 0 & 32.60 & 67.39 \\
Ceftriaxone+tazobactum & 60.86 & 28.26 & 10.86 \\
\hline
\end{tabular}

due to secondary invasion by opportunist bacteria as a result of lowered resistance of the udder [14]. The presence of pure culture and mixed cultures was ascertained by the different types of colonies growing on the isolation plate and their morphological and staining characteristics. The pure culture revealed the presence of Staphylococcus, Streptococcus and E. coli whereas the colonies picked up at random from the mixed cultures showed the presence of Pseudomonas spp., Proteus spp., Corynebacterium spp. and Bacillus spp. along with few samples positive for Listeria spp. and Klebsiella spp, in addition to the organisms isolated from pure culture. The conclusion regarding the identity of Staphylococcus, Streptococcus and E. coli was made on basis of their motility, staining, cellular morphology, characteristic growth on selective media (MSA, EMB and blood agar), hemolytic pattern on blood agar, biochemical test and sugar fermentation properties whereas the inference regarding other isolates was made as per the methods followed above except for the growth on selective media. Isolation of these bacteria from milk samples has been previously reported $[2,14,15,16]$.

Of the 144 samples, Staphylococcus was found in
Table-3. Antibiogram of Staphylococcus isolates

\begin{tabular}{|c|c|c|c|}
\hline Antibiotic & $\begin{array}{c}\text { Highly } \\
\text { sensitive (\%) }\end{array}$ & $\begin{array}{c}\text { Moderately } \\
\text { sensitive (\%) }\end{array}$ & Resistant (\%) \\
\hline Chloramphenicol & 77.94 & 10.29 & 5.55 \\
\hline Amoxycillin & 0 & 44.11 & 55.88 \\
\hline Enrofloxacillin & 88.23 & 10.29 & 1.47 \\
\hline Streptomycin & 14.70 & 54.41 & 30.88 \\
\hline Levofloxacin & 88.23 & 8.82 & 2.94 \\
\hline Pencillin-G & 0 & 17.64 & 82.35 \\
\hline Gentamicin & 73.52 & 26.47 & 0 \\
\hline Ciprofloxacin & 75 & 25 & 0 \\
\hline Ofloxacin & 55.88 & 33.82 & 10.29 \\
\hline Cephalexin & 22.05 & 22.05 & 55.88 \\
\hline Oxytetracycline & 11.76 & 55.88 & 32.35 \\
\hline Cefixime & 0 & 33.82 & 66.17 \\
\hline Ceftriaxone+tazobactun & um 66.17 & 22.05 & 11.76 \\
\hline
\end{tabular}

Table-5. Antibiogram of E. coli isolates

\begin{tabular}{lccc}
\hline Antibiotic & $\begin{array}{c}\text { Highly } \\
\text { sensitive (\%) }\end{array}$ & $\begin{array}{c}\text { Moderately } \\
\text { sensitive (\%) }\end{array}$ & Resistant (\%) \\
\hline Chloramphenicol & 90 & 10 & 0 \\
Amoxycillin & 30 & 20 & 50 \\
Enrofloxacillin & 83.33 & 10 & 6.66 \\
Streptomycin & 43.33 & 50 & 6.66 \\
Levofloxacin & 96.66 & 3.33 & 0 \\
Pencillin-g & 0 & 3.33 & 96.66 \\
Gentamicin & 50 & 40 & 10 \\
Ciprofloxacin & 83.33 & 3.33 & 13.33 \\
Ofloxacin & 53.33 & 36.66 & 10 \\
Cephalexin & 10 & 33.33 & 56.66 \\
Oxytetracycline & 23.33 & 10 & 66.66 \\
Cefixime & 0 & 16.66 & 83.33 \\
Ceftriaxone+tazobactum & 50 & 23.33 & 26.66 \\
\hline
\end{tabular}

$47 \%$, whereas Streptococcus and E. coli in $32 \%$ \& $21 \%$ of the samples respectively [Table-1]. The predominance of Staphylococcus isolates over Streptococcus in subclinical cases of mastitis has been highlighted in the study of many workers previously $[17,18]$. Though high prevalence of Staphylococcus spp. followed by $E$. coli has been cited in the work of several other workers $[2,19,20,21]$. But in the present study, the period of investigation showed a high prevalence of Staphylococcus followed by Streptococcus, and E. coli. Similar findings were also observed by several workers in different parts of the globe [18, 22, 23, 24]. However, Gitau et al. [25] have found the prevalence of Streptococcus species to be highest in mastitis.

Antibiogram of the isolates: It was revealed during the isolation and identification that Staphylococcus, Streptococci and E. coli are the major pathogens responsible for clinical and sub clinical cases of mastitis and study of their response to various antibiotics will help in the management and control of the condition in day to day animal husbandry practices in an efficient way. On carrying out the antibiogram of the targeted isolates (Staphylococcus spp., Streptococcus 
spp., E. coli.) it was found that most of the isolates were showing high sensitivity towards Chloramphenicol, Enrofloxacin, Levofloxacin, Ciprofloxacin while resistance pattern was more evident for some classical antibiotics like Pencillin-G, Cephalexin, and Amoxycillin. The sensitivity pattern for Streptomycin, Ceftriaxone, Gentamicin and Oxytetracycline showed an alarming indication of increasing resistance among the bacterial organisms to these therapeutic agents [Table-2]. This study was in close agreement with many workers [22, 26]. Farooq et al. [23] during their study period have found that Norfloxacin, Gentamicin and Chloramphenicol were the most effective drugs where as Amoxycillin, Kanamycin, Sulphamethaxazole, Streptomycin and Penicillin-G showed lesser effectiveness against mastitis isolates. Harini et al. [20] screened milk samples and found bacterial isolates highly sensitive for Ciprofloxacin, Ofloxacin, Enrofloxacin, Gentamicin and Chloramphenicol, with pattern of resistance towards Colistin, Neomycin, Streptomycin, Penicillin and Tetracycline. Similarly Jeykumar et al. [21] found Enrofloxacin to be most effective among the antibiotics whereas Sumathi et al. [2] reported Gentamicin to be most effective among the antimicrobials used in study.

Antibiogram of Staphylococcus isolates: Staphylococcus is the most important and prevalent mastitogenic organism occurring globally, including India [2]. In case of studies relating to Staphylococcus, Unakal et al. [5] have found that the highest numbers of Staphylococcus aureus isolates were susceptible to Ceftriaxone followed by Cefotaxime, Methicillin, Ciprofloxacin, Erythromycin, Amikacin, Gentamicin, Amoxycillin, Ampicillin, whereas the lowest susceptibility was shown in Penicillin-G. However the present study contrastingly showed a decreasing trend of sensitivity of Staphylococcus towards Ceftriaxone combination of drugs [Table-3], but was well in agreement with other reports that stated newer drugs like Levofloxacin, Enrofloxacin, Chloramphenicol and Gentamicin were effective in treatment of Staphylococcal mastitis [26].

Antibiogram of Streptococcus isolates: Streptococcus being second highest in the list following the current study is responsible for chronic contagious bovine mastitis and understanding its susceptibility towards antimicrobials is very essential. Jain et al. [27] found the higher succeptibility of Streptococcus isolates towards Enrofloxacin and Gentamicin, whereas Mahantesh et al. [4] reported higher susceptibility to Tetracycline and Chloramphenicol. Similar concordance has been found in the current study where it was found that the Streptococcus isolates were most susceptible to Enrofloxacin, Levofloxacin and Ciprofloxacin [Table-4].

Antibiogram of E. coli isolates: The incidence of $E$. coli mastitis may have been due to poor hygienic conditions, as $E$. coli originates from the cow's environment and infect the udder via the teat canal [28]. In the current study it was observed that the $E$. coli isolates were most sensitive toward Levofloxacin and Chloramphenicol followed by Enrofloxacin, Ciprofloxacin, Ofloxacin and Gentamicin [Table-5]. However this was in contrast to the study of Moges et al. [22] who found $E$. coli to be highly susceptible to Chloramphenicol and Clindamycin. Similarly Khan et al. [29] showed that $E$. coli were sensitive to Gentamicin, Ciprofloxacin, Chloramphenicol, Cephalothin, Amoxycillin and Oxytetracycline.

The increased resistance to these therapeutic agents can be attributed to injudicious use of antibiotics in the mastitis cases $[4,14,17,20,21,26,30]$ along with negligence towards the bacteriological examination of the suspected milk. Though species, regional and managemental variations leads to variation of results in the antibiogram study but also the preferences of antibiotics used by various workers leads to inaccurate correlation among the studies relating to the sensitivity of mastitogenic isolates towards antibiotics. But even with the study of findings of various workers, the present study draws the conclusion that newer drugs like Levofloxacin and Enrofloxacin are very much effective for treatment of mastitis. But development of resistance in bacteria against these agents cannot be ruled out in the near future if injudicious use of antibiotics continues further.

\section{Conclusion}

Development of resistance among bacteria is a matter of great concern in the field of veterinary medicine especially when the organisms renders an animal unproductive, thus posing a direct threat to country's economy. So as a well planned therapy is very essential in control and cure of mastitis, conducting an antibiogram profile of the mastitogenic organisms provides a clear insight towards management of mastitis. In the present study, the prevalence of Staphylococcus was found to be maximum followed by Streptococcus and E. coli among the isolated organisms. These three isolates showed high sensitivity towards antibiotics like Levofloxacin and Enrofloxacin. Considering the clinical and economic aspect of the disease, awareness is required among farmers and clinicians for preventing the drugs from falling into the resistant category. Accurate diagnosis of mastitis, isolation and identification of causal organisms, establishment of correct in vitro antibiogram along with proper food and hygienic status of the animal is very much essential to prevent mastitis cases and economic losses thereof.

\section{Authors' contributions}

NNM, LNS and HKP have conceived, planned and designed the study. PD, SSP, SR have isolated, carried out the antibiogram profile, analysed and kept a due record of the data. Manuscript was framed and drafted by NNM, LNS under the guidance of HKP. All authors read and approved the final manuscript.

\section{Acknowledgements}

The authors are thankful to the Dean, College of 
Veterinary Science and Animal Husbandry, Bhubaneswar and Director, Central Clinic, for their support and cooperation in carrying out the study. The fund was received from the Department of Veterinary Microbiology, Veterinary College, Bhubaneswar, Orissa.

\section{Competing interests}

The authors declare that they have no competing interests.

\section{References}

1. Radostitis, O.M., Gay, C.C., Blood, D.C. and Funchcliff, K. W. (2000) Veterinary medicine: Atext book of the disease of cattle, sheep, goat, horse and pigs. 9th Edition W.B.Saunders, London.

2. Sumathi, B. R., Veeregowda, B. M. and Gomes, A.R. (2008) The occurrence and antibiogram of bacterial isolates clinical bovine mastitis. Veterinary World 1(8): 237-238.

3. Ranjan, R., Gupta, M. K., Singh, K.K. and Jha, D. K. (2008) Comparative efficacy of Papanicolaou stain and Leishman stain in the cytological study of bovine mastitis. Indian J. Vet. Pathol.32: 277-279.

4. Mahantesh, M. K. and Basappa, B. K. (2011) Prevalence and antimicrobial susceptibility of bacteria isolated from bovine mastitis. Adv. Appl. Sci. Res 228(6):229-235.

5. Unakal, C. G. and Kaliwal, B. B. (2010) Prevalence and antibiotic susceptibility of Staphylococcus aureus from bovine mastitis. Veterinary World 3(2):65-67.

6. Miltenburg, J. D., de Lange D., Crauwels, A.P.P., Bongers, J.H., Tielen, M.J.M., Schukken, Y.H. and Elbers, A.R.W. (1996) Incidence of clinical mastitis in a random sample of dairy herds in the southern Netherlands. Vet. Rec. 139: 204207.

7. Adesola A. E. (2012) Antimicrobial Resistance Pattern of Streptococci and Staphylococci Isolated from Cases Of Bovine Clinical Mastitis in Nigeria. Nat. Sci. 10(11):96-101.

8. Acar, J. and Rostel, B. (2001) Antimicrobial resistance: An overview. Rev. Sci. Technol. 20: 797-810.

9. Cruickshank, R., Duguid, J.P., Marmion, B.P. and Swain, R.H.A. (1975) Medical Microbiology. Vol. II, 12th edn, Crurchill Livingstone, New York, 31-57p \& 96-218p.

10. Holt, J.G. (1994) Bergey's Manual of Determinative Bacteriology, 9th Edition, Williams and Wilkins, Baltimore, Maryland, USA.

11. Garrity, G.M., Brenner, D.J., Krieg, N.R. and Staley, J.T. (2005) Bergey's manual of Systemic Bacteriology, (Vol.-2, Part: A-2, Part: A-C, 2nd Edition, Springer-Verlag,).

12. Bauer, A.W., Kirby, W.M., Sherriz, J.C. and Tuck, N. (1966) Antibiotic susceptibility testing by standardized single disc method. American J. Clin. Pathol. 45 : 493-496.

13. Ramprabhu, R., Rajeshwar, J.J., Jayram, N. and Piramanayagm, S. (2004) Comparative antibiogram and clinical efficacy of utraiaxone in bovine mastitis. Indian Vet. J. $81: 863-864$.

14. Ranabijuli, S., Palai, T.K., Sarangi, L.N., Sardar, K.K. and Panda, H.K. (2009) In vitro antibiotic sensitivity pattern of bacterial isolates from clinical cases of Bovine Mastitis in and around Bhubaneswar. Indian J. Comp. Microbiol. Immunol. Infect. Dis.30(1):57-58.

15. Raychoudhary, P. and Dutta, T.K. (2009) Prevalence and antibiotic sensitivity pattern of bacteria from bovine mastitis in Mizoram. Indian J. Anim. Sci. 79 (5) : 483-485.

16. Sarangi, L.N., Panda, H.K., Priyadarshini, AA., Sahoo, S.,Palai, T.K., Ranabijuli, S., Senapati, S. and Mohanty, D.N. (2009a) Prevalence of Listeria species in milk sample of cattle of Orissa. Indian J. Comp. Microbiol. Immunol. Infect. Dis. 30(2): 135-136.

17. Paul, W. M., Parthiban, M., Menaka, R. and Nainar, A. M. (2000) The occurrence and antibiogram of bacterial isolates from milk samples of bovine subclinical mastitis. Indian J. Anim. Health 39(2):79-81.

18. Elango, A., Doraisamy, K.A., Rajarajan, G. and Kumaresan, G. (2010) Bacteriology of sub clinical mastitis and antibiogram of isolates recovered from cross bred cows. Indian J. Anim. Res. 44 (4): 280 - 284.

19. Aarestrup, F.M, Wegener, H.C., Rosdahl, V.T. and Jensen, N.E (1995) Staphylococcal and other bacterial species associated with intramammary infections in Danish dairy herds. Acta Veterinaria Scandinavica 36:475-487.

20. Harini, H. and Sumathi, B.R. (2011) Screening of bovine milk samples for sub-clinical mastitis and antibiogram of bacterial isolates. Veterinary World 4(8):358-359.

21. Jeykumar, M., Vinodkumar, G., Bashir Bimal, P. and Krovvidi, S. (2013) Antibiogram of mastitis pathogens in the milk of crossbred cows in Namakkal district, Tamil Nadu. 6: 354-356

22. Moges, N., Asfaw,Y., Belihu, K. and Tadesse, A. (2011) Antimicrobial Susceptibility of Mastitis Pathogen from small holder Dairy Herd in and around Gondar, Ethopia. $J$. Anim. Vet. Adv.10(12):1616-1622.

23. Farooq, A. A., Inayat, S., Akhtar, M.S. and Mushtaq, M. (2008) Prevalence of mastitis and antibiotic sensitivity of bacterial isolates recovered from nili-ravi buffaloes. J. Anim. Pl. Sci. 18(2-3): 76-77.

24. Kanhar, N.C., Ranaijuli, S., Sarangi, L.N., Priyadarshini, A., Palai, T.K., Sardar, K.K. and Panda, H.K. (2012) Effect of season on the involvement of etiological agents in bovine mastitis of Odisha. J.Interacad. 16 (2a):499-503.

25. Gitau, G. K., Wabacha, J. K., Mulei, C. M., Ndurumo, S. and Nduhiu, J. M. (2011) Isolation rates and antimicrobial sensitivity patterns of bovine mastitis pathogens in periurban area of Nairobi, Kabete, Kenya. Ethiop. Vet. J. 15 (1): $1-13$.

26. Sarangi, L.N., Panda, H. K., Priyadarshini, PA., Palai, T.K., Ranabijuli, S., Sahoo, S.,?Dash A.K., Mohanty, N.N., Kar, B.C. and Mohanty, D.N. (2009b) Antibiogram and drug resistance of Staphylococcus aureus isolated from bovine clinical and subclinical mastitis. Journal of Research, O.U.A.T., Bhubaneswar. 27 (1\&2): 136-138.

27. Jain, B., Tewari, A., Bhandari, B. B. and Jhala, M. K. (2012) Antibiotic resistance and virulence genes in Streptococcus agalactiae isolated from cases of bovine subclinical mastitis. Vet. Arhiv. 82 (5): 423-432.

28. Bradley, A. J. (2002) Bovine mastitis an evolving disease. The Vet. J. 164: 116-128.

29. Khan, A.Z., Khan, A., Hayat, C. S., Munir, Z. and Ayaz, U. (2004) Prevalence of mastitis in buffaloes and antibiotics sensitivity profiles of isolates. Pak. J. Life Soc. Sci.2(1): 73-75.

30. Mubarack, H. M., Doss, A., Vijayasanthi, M. and Venkataswamy, R. (2012) Antimicrobial drug susceptibility of Staphylococcus aureus from subclinical bovine mastitis in Coimbatore, Tamilnadu, South India. Veterinary World 5(6): 352-355. 